Marcelo Paulo Maggio ${ }^{1}$ Sueli Gandolfi Dallari ${ }^{1}$

\title{
A EFETIVAÇÃO JURÍDICO-POLÍTICA DO DIREITO À SAÚDE NO SUPREMO TRIBUNAL FEDERAL: A REFERÊNCIA PARADIGMÁTICA DA SL 47-AGR/PE
}

The legal-political realization of the right to health in the Brazilian Supreme Court: the paradigmatic reference of SL 47-AgR/PE

${ }^{1}$ Universidade de São Paulo. São Paulo/SP, Brasil.

Correspondência: Marcelo Paulo Maggio. E-mail: marcelopmaggio@gmail.com.

Recebido em: 16/12/2015. Revisado em: 06/06/2016. Aprovado em: 19/06/2016. 


\section{RESUMO}

A saúde é direito fundamental, essencial à proteção e à manutenção da vida, pressuposto da dignidade da pessoa humana, possuindo papel de destaque na complexa realidade social que integramos. Como tal, deve ser incansavelmente protegido, respeitado e garantido mediante políticas sociais e econômicas, em prol do interesse de cada indivíduo e da própria sociedade, consoante, inclusive, previsto na ordem constitucional. Nesse contexto, instado a se pronunciar, o Supremo Tribunal Federal, na qualidade de guardião da Constituição, tem a incumbência de proferir respostas capazes de proporcionar o bem-estar físico, mental e social devido a todos, em sintonia com o constitucionalmente previsto, no intuito de garantir adequado alcance jurídico e/ou político em suas decisões. Por isso, mostra-se relevante avaliar se a atuação da Corte, frente a casos concretos, efetivamente consegue respeitar a boa técnica jurídica e/ou política e, com essa finalidade, por enquadrá-la na condição de paradigma, optou-se por eleger o decisum prolatado no âmbito da Suspensão de Liminar 47 - Agravo Regimental do Estado de Pernambuco.

\section{Palavras-Chave}

Direito à Saúde; Representatividade Jurídica; Representatividade Política; Supremo Tribunal Federal.

\section{ABSTRACT}

Health is a fundamental right, essential for protection and maintenance of life, assuming the dignity of the human person, having an important role in the complex social reality of which we are a part. As such, the right to health should be constantly protected, respected and guaranteed through social and economic politics, in favor of the interest of each individual and his or her own community. In this context, when called upon to rule, the Brazilian Supreme Court, as guardian of the Constitution, has the duty to deliver responses capable of providing physical, mental and social well-being to all, aligned with the provisions of the Constitution, in order to ensure appropriate legal and/or political significance in its decisions. Therefore, it is relevant to assess if the activities of the Court, in concrete cases, can effectively respect the best legal practices and/or policy and, for this purpose, and to fit it into this paradigm, it was selected a specific decisum.

\section{Keywords}

Brazilian Supreme Court; Legal Representation; Political Representation; Right to Health. 


\section{Introdução}

O conteúdo normativo constitucional serve para definir os direitos e garantias fundamentais, delinear a estrutura dos órgãos do Estado e limitar a prática de abusos e arbitrariedades, a ponto de viger o princípio da supremacia da Constituição sobre as leis e os demais atos normativos, o que impõe a necessidade de a legislação infraconstitucional guardar coerência, simetria e respeito ao constitucionalmente previsto.

Assim, a Constituição funciona como núcleo normativo central, condutor de como o sistema jurídico e político necessita ser concebido e executado, indicador de parâmetros do processo democrático e do debate público, e balizador não apenas da proteção que merece recair sobre direitos fundamentais, mas também da forma como o Estado deve se organizar e procurar implantar políticas públicas.

Em especial, apresenta a ordem constitucional expressa previsão no sentido de que a saúde se constitui em direito de todos. Por isso, a organização e a disponibilização de ações e serviços de saúde devem se dar através de contínuos e eficientes atos de gestão, prestação e regulação, de modo a assegurar, com adequado planejamento e financiamento, a atenção devida em saúde. Ademais, diante da contínua mutabilidade das questões econômicas, sociais, culturais, políticas e científicas, o setor de saúde constantemente precisa ser projetado para que suas iniciativas se mantenham progressivamente atuais e resolutivas.

Nesse contexto, a partir do arranjo institucional do poder e da negociação política realizada para a entrada em vigor da Constituição Federal de $1988^{1}(\mathrm{CF} / 88)$, reservou-se ao Supremo Tribunal Federal (STF) o dever de atuar como seu guardião, competindo-lhe, por isso, apreciar situações reveladoras de antinomia ao disposto sobre saúde no ordenamento constitucional.

No enfrentamento das questões de sua competência, a partir do ano de 2007 - alicerçando-se em situações compreendidas como de repercussão geral e reveladoras de interesse público, e procurando externar à sociedade o propósito de melhor conhecê-las e julgá-las, bem como assegurar maior legitimidade à sua atuação -, o STF começou a convocar audiências públicas, convidar pessoas com expertise em determinadas áreas do saber e possibilitar que interessados requeressem suas respectivas participações nesses atos. A primeira audiência tratou da pesquisa com células-tronco embrionárias e foi realizada em 20 de abril de 2007; a segunda abordou a importação de pneus usados e aconteceu em 27 de junho de 2008; e a terceira tratou da interrupção de gravidez, enquanto decorrência do diagnóstico de feto anencéfalo e foi realizada nos dias 26 e 28 de agosto de 2008 e 4 e 16 de setembro de 2008.

${ }^{1}$ BRASIL. Constituição da República Federativa do Brasil de 1988. Disponível em: <http://www.planalto.gov. br/ccivil_03/constituicao/constituicaocompilado.htm>. Acesso em: 31 jan. 2017. 
A quarta audiência pública, realizada nos dias 27, 28 e 29 de abril e 4, 6 e 7 de maio, todos do ano de 2009, teve o propósito específico de esclarecer questões técnicas, científicas, administrativas, políticas, econômicas e jurídicas relacionadas às ações e aos serviços de saúde, em vista do número cada vez maior de demandas que chegavam à apreciação do STF tendo como ponto principal a existência de conflitos relacionados à obrigação do Estado (gênero), a partir do disciplinado na $\mathrm{CF} / 88$, de fornecer medicamentos, suplementos alimentares, órteses e próteses, disponibilizar leitos em hospitais, providenciar a realização de procedimentos cirúrgicos, além de custear outros tratamentos afetos à seara sanitária.

A partir das experiências e dos dados colhidos na referida audiência, o Tribunal Pleno do STF reuniu-se para então decidir, dentre outros, o Agravo Regimental na Suspensão de Liminar n. 47 (SL 47-AgR/PE).

O resultado produzido e o contido nos votos proferidos no âmbito desse julgado serviram e ainda servem de paradigma para orientar a solução que se costuma proporcionar às questões que possuem a saúde pública como objeto, tornando importante avaliar se, qualitativamente, em extensão (horizontal) e profundidade (vertical) a resposta externada por aquela Corte pode ser compreendida como jurídica e/ou politicamente adequada.

A análise proposta principia-se com ponderações sobre o direito à saúde, com a finalidade de apenas traçar seus contornos gerais. Posteriormente, passa-se a destacar o processado no âmbito do SL 47-AgR/PE. Depois de situar o leitor acerca de suas particularidades, apresentam-se, na sequência, comentários de cunho geral sobre o papel do STF quando provocado a se pronunciar sobre circunstâncias afetas a políticas públicas de saúde. Posteriormente, com base nessas ponderações, passa-se a efetivamente tecer considerações a respeito do decidido no citado agravo, com o propósito maior de verificar se possui eficácia jurídica e política, assim como se os efeitos decorrentes podem ser compreendidos como positivos em prol do fortalecimento do direito à saúde.

Por fim, as conclusões terão o objetivo de fazer um balanço dos argumentos expostos.

\section{I. $\quad 0$ direito à saúde}

Com o intuito de fornecer o alicerce necessário à sustentação da temática proposta, pode-se afirmar que, simultaneamente ao processo de transformação do homem e da sociedade, o direito ${ }^{2}$ passou a tutelar bens considerados relevantes, rol

\footnotetext{
${ }^{2}$ Entende-se que o Direito, amparado em sistema normativo, de forma justa e eficaz, encontra-se presente no cotidiano do ser humano, à disposição da sociedade, a fim de permitir a superação das adversidades e divergências, oportunizando a vivência do bem comum.
} 
no qual a saúde se amolda com perfeição diante de sua fundamentalidade ${ }^{3}$, pois é necessária ao bem-estar físico, mental e social, capaz de viabilizar a garantia da própria vida dos indivíduos - configurando-se, portanto, pressuposto da dignidade da pessoa humana e, como tal, deve ser incansavelmente protegida e respeitada.

Todavia, como a saúde pode ser conceituada? Por que deve ser compreendida como um direito? A preocupação de responder a essas indagações mostra-se procedente para melhor compreender a saúde e, desse modo, fornecer-lhe não somente a justa proteção, mas também assegurar as condições necessárias para seu contínuo aperfeiçoamento, em proximidade com o querer social.

Ao examinar de forma percuciente e sempre atual o assunto, Dallari destacou em artigo de sua autoria que a preocupação de conceituar a saúde acompanha a história da humanidade, a ponto de o filósofo grego Hipócrates, no século IV a.C., ter ressaltado que as características da "cidade e do tipo de vida de seus habitantes" produzem influência sobre a saúde das pessoas, servindo a adequada compreensão de tais fatores como parâmetro para que os médicos consigam evitar o erro no tratamento das doenças. Por sua vez, na primeira metade do século XVI, ainda segundo o pontuado por Dallari, Paracelso enalteceu a relevância do plano exterior ("leis da física da natureza e fenômenos biológicos", assim como do "ambiente de trabalho") para o melhor entendimento do "organismo humano". Ao seu turno, somando esses elementos, consoante também ressalta Dallari, o filósofo Engels assinalou que o estágio de saúde da população depende da "cidade", do "tipo de vida de seus habitantes" e do espaço laboral. No trilhar conceitual, caminhou-se em direção ao entendimento da saúde como mera ausência de doenças, a partir de concepção cartesiana que equiparava o corpo humano a uma "máquina”, passível de ser conservada. Sequencialmente, no século XIX, a partir de visão mecanicista, concebeu-se a doença como algo que necessitava receber terapêutica especializada, período no qual os trabalhos de Pasteur e Koch provaram as causas da origem de algumas moléstias. Com a revolução industrial, de um lado enfatizou-se que o grau de saúde depende de "variáveis relacionadas ao meio ambiente, ao trabalho, à alimentação e à moradia", enquanto que, de outro, o conhecimento acerca das causas de certas doenças permitiu tratá-las e curá-las, reforçando a ideia de saúde como ausência de enfermidade. A controvérsia teve fim a partir da "intervenção de fatores políticos" e da "experiência" de duas guerras mundiais - quando, então, percebeu-se que a conceituação de saúde merecia ser visualizada a partir da junção do "equilíbrio interno do homem com o ambiente", pois possui status fundamental e se constitui em direito humano.

\footnotetext{
3“Art. $2^{\circ}$ A saúde é um direito fundamental do ser humano, devendo o Estado prover as condições indispensáveis ao seu pleno exercício." BRASIL. Lei n. 8.080, de 19 de setembro de 1990. Dispõe sobre as condições para a promoção, proteção e recuperação da saúde, a organização e o funcionamento dos serviços correspondentes e dá outras providências. Disponível em: <http://www.planalto.gov.br/ccivil_03/ leis/L8080.htm>. Acesso em: 31 jan. 2017.

${ }^{4}$ DALLARI, Sueli Galdolfi. O direito à saúde. Revista de Saúde Pública, São Paulo, v. 22, n. 1, p. 58-59, 1988. Disponível em: <http://www.scielo.br/pdf/rsp/v22n1/08.pdf>. http://dx.doi.org/10.1590/S0034-89101988000100008..
} 
Por se mostrar indispensável à formação, ao desenvolvimento, à manutenção e à sobrevivência adequados do ser humano, a saúde tem como inerente a sua definição a fundamentalidade ${ }^{5}$, até porque se apresenta como requisito indispensável para a fruição com dignidade dos demais direitos. A esse caráter essencial merece ainda somar-se o fato de que a saúde, em oposição ao desequilíbrio orgânico - indicador de doença -, guarda íntima proximidade com a condição de harmonia ou de equilíbrio físico, psíquico, econômico e cultural do próprio indivíduo consigo mesmo e com o meio social no qual está inserido, apresentando-se mais bem configurada quando se observa adaptabilidade do ser humano frente aos desafios do cotidiano.

A somatória dessas circunstâncias indica a indispensabilidade de o enfoque sobre a saúde ser de natureza não linear, atentando-se para os múltiplos fatores ou dimensões que a circundam. Dessa forma, é plenamente justificável que a discussão sobre seu conteúdo e sua extensão seja objeto de debate democrático por "toda a sociedade" ${ }^{6}$ à vista da mutabilidade de situações que podem caracterizá-la. Por exemplo, se hoje a preocupação na esfera sanitária, a partir de dados epidemiológicos, é de fortalecer a atenção básica prestada no Município " $X$ ”, no ano vindouro o contexto passará a demonstrar que o esforço para garantir a eficaz tutela da saúde deve recair, através dos registros colhidos e do entendido como mais relevante pela participação popular, sobre a superação do déficit de leitos de média e de alta complexidade apurados. De igual modo, na hipótese de a gestão da saúde formular e implantar na atualidade uma política pública de combate à dengue, as circunstâncias de fato, extremamente versáteis, passarão a exigir que futuramente, por exemplo, a atuação deva passar a focar o combate a outras endemias, tais como a tuberculose e a febre amarela.

Em síntese, a caracterização da saúde não pode ser fechada, mas sim aberta à complexidade que a caracteriza, sendo certo que, diante das diversas possibilidades resultantes, é democraticamente importante permitir, ouvir e levar em consideração o socialmente pontuado como preponderante a respeito.

Vê-se, então - notadamente na atualidade, por força de matriz constitucional (artigo 197, da CF/88) -, que o fato de a saúde ter sido explicitamente qualificada como de relevância pública não deixa espaço para qualquer discussão acerca de sua essencialidade e, da mesma forma, impõe ao Estado (gênero) que atue diligentemente em sua prestação através de políticas públicas, a fim de que seja eficaz. Por isso,

\footnotetext{
${ }^{5}$ Concebida pela Organização Mundial da Saúde como o "estado completo de bem-estar físico, mental e social e não simplesmente como a ausência de doença ou enfermidade". Prevista como direito na Declaração Universal dos Direitos Humanos nos seguintes termos: "Artigo 25. 1. Todo ser humano tem direito a um padrão de vida capaz de assegurar a si e a sua família saúde e bem estar, inclusive alimentação, vestuário, habitação, cuidados médicos e os serviços sociais indispensáveis, e direito à segurança em caso de desemprego, doença, invalidez, viuvez, velhice ou outros casos de perda dos meios de subsistência fora de seu controle.". PORTAL BRASIL. Declaração Universal dos Direitos Humanos. Brasília, 1998. Disponível em: <http://unesdoc.unesco.org/images/0013/001394/139423por.pdf>. Acesso em: 31 jan. 2017.

${ }^{6}$ DALLARI, Sueli Galdolfi. A saúde do brasileiro. São Paulo: Moderna, 1987. p. 6.
} 
a prestação deve ser (a) universal: acesso garantido às ações e serviços de saúde para toda a população, em todos os níveis de assistência, sem a possibilidade de imposição de qualquer preconceito ou privilégio; (b) igualitária: atenção à saúde com igualdade, tratando os iguais de forma igualitária e os desiguais de forma desigual, com vistas a alcançar a igualdade substancial; e (c) integral: a oferta de saúde deve incluir ações de prevenção, recuperação e tratamento em qualquer nível de complexidade, levando-se em consideração que o ser humano é uma totalidade, um todo indivisível, até porque não se pode prestar "meia-saúde", o que é a toda vista inaceitável.

Para tanto, o adequado financiamento, destinado a suprir as despesas e fornecer os créditos necessários à satisfação das ações e serviços de saúde devidos à pessoa humana, constitui dever impostergável da União, dos estados, do Distrito Federal e dos municípios ${ }^{7}$. Aliás, necessita o poder público consignar na lei orçamentária e, quando necessário, buscar a suplementação das dotações necessárias para o alcance progressivo de prestações sanitárias e concretizar a gradativa implementação e execução de políticas públicas de saúde.

Caso assim não ocorra, diante da importância do correto e concreto financiamento das ações e serviços, a ordem constitucional incluiu, por exemplo, dentre as hipóteses de intervenção da União nos estados, no Distrito Federal e nos municípios, a não aplicação dos percentuais do orçamento próprio no custeio das ações e serviços públicos de saúde (artigo 34, inciso VII, alínea "e", e artigo 35, inciso III, ambos da CF/88). Dessa forma, há de se assegurar orçamento público mínimo para a efetividade da oferta e ampliação dos serviços, a partir de dados epidemiológicos.

Como se não bastasse, os recursos da saúde necessitam ser aplicados exclusivamente através do fundo de saúde inerente à União, ao Distrito Federal e a cada

\footnotetext{
${ }^{7}$ Com a entrada em vigor da Emenda Constitucional n. 29/2000, ampliou-se e tornou-se mais preciso o conteúdo do artigo 198 da $\mathrm{CF} / 88$, acrescentando-lhe os parágrafos $2^{\circ}$ e $3^{\circ}$ e respectivos incisos, bem como o artigo 77 e parágrafos no Ato das Disposições Constitucionais Transitórias (ADCT). Essas regras determinaram, em síntese, a aplicação de um percentual mínimo de recursos provenientes do Tesouro da União, dos estados, do Distrito Federal e dos municípios em atividades finalísticas de saúde pública. No entanto, apesar do registrado nessas normas constitucionais, os entes públicos costumavam justificar o financiamento inadequado a que davam causa, alegando que: (a) esses preceitos deveriam sofrer disciplina normativa através da edição de lei complementar; (b) ainda por ausência de lei complementar, não havia nenhum desenho acerca do significado da expressão "ações e serviços públicos de saúde" capaz de vincular a atuação administrativa sanitária ao que realmente pode ser considerado como de saúde. Para impedir a continuidade dessas tentativas de justificativa, entrou em vigor a Lei Complementar n. 141, de 13 de janeiro de 2012 que, ao regulamentar o disposto nos artigo 198 da Carta Magna, não só explicitou o que consistem ações e serviços de saúde (artigo $2^{\circ}$ ), mas também expressamente definiu os recursos mínimos a serem aplicados por União, estados, Distrito Federal e municípios, a título de financiamento. A União aplicará, anualmente, em ações e serviços públicos de saúde, o montante correspondente ao valor empenhado no exercício financeiro anterior, apurado nos termos desta Lei Complementar, acrescido de, no mínimo, o percentual correspondente à variação nominal do Produto Interno Bruto (PIB) ocorrida no ano anterior ao da lei orçamentária anual. Os estados e o Distrito Federal, por sua vez, aplicarão, anualmente, no mínimo $12 \%$ de seus recursos orçamentários. Por fim, os municípios aplicarão, anualmente, no mínimo 15\% de seus recursos orçamentários. Sobre o tema, interessante a consulta aos seguintes julgados: STF. AC 3389 MC-Ref, Rel. Min. Celso de Mello, Trib. Pleno, j. em 1.8.2013, publ. em 29.8.2013 e STF. ACO 1609 AgR, Rel. Min. Luiz Fux, $1^{\circ}$ Turma, j. 19.5.2015, publ. em 2.6.2015.
} 
um dos estados e municípios. Esse fundo deve ser gerenciado exclusivamente pelo titular da pasta da Saúde, de forma a assegurar que todos os valores destinados às ações e serviços permaneçam lá concentrados, visando a proporcionar transparência dos recursos disponíveis e a efetiva aplicação em prol de ações e serviços de saúde e permitindo adequado planejamento, organização e controle dos recursos orçamentários pelos órgãos fiscalizadores e pela própria comunidade.

A partir dessas premissas, observa-se a necessidade de os entes públicos garantirem fundamentalidade ao direito à saúde. A consecução dessa tarefa dá-se através da contínua implantação e execução de políticas públicas, as quais necessitam receber recursos para, com responsabilidade financeira, tornarem garantidos o atendimento das demandas sanitárias do povo e a transformação dos comandos abstratos presentes no conjunto normativo em eficaz tutela jurídica concreta - até porque, frente a direitos como o à saúde, o caráter vinculado passa a assumir preponderância, com justo afastamento da discricionariedade e da mera promessa constitucional.

Afinal, o direito à saúde possui proteção constitucional e se deve atuar no sentido de fazê-lo alcançar e permanecer no patamar que lhe fora reservado constitucionalmente no Estado de Direito.

Logo, na interpenetração do direito $^{8}$ na seara político-sanitária, uma vez não respeitados os parâmetros constitucionais reservados à saúde 9 , apresenta-se possível buscar a atuação jurisdicional do STF, servindo de exemplo o julgamento do tema concreto escolhido e destacado a seguir.

\section{II. o Agravo Regimental na Suspensão de Liminar n. 47 do STF}

Resumidamente, a decisão selecionada trata de agravo regimental ${ }^{10}$ interposto pelo Estado de Pernambuco contra o julgamento proferido pelo então Presidente do STF, Nelson Jobim, ao indeferir o pedido de suspensão dos efeitos da liminar ${ }^{11}$ concedida pelo Juízo Federal da $8^{\text {a }}$ Vara de Petrolina/PE, em reforço ao

\footnotetext{
${ }^{8}$ Diante da percepção dessas premissas, ganha realce o Direito Sanitário, através do qual, em atenção aos reclamos da sociedade, com autonomia científica, passou-se a adequadamente tutelar o direito à saúde, por intermédio da compreensão de que se constitui "conjunto de normas jurídicas que têm por objeto a promoção, prevenção e recuperação de saúde de todos os indivíduos que compõem o povo de determinado Estado, compreendendo, portanto, ambos os ramos tradicionais em que se convencionou dividir o direito: público e privado".DALLARI, Sueli Galdolfi. Direito sanitário. In: MINISTÉRIO DA SAÚDE. Direito sanitário e saúde pública. Brasília: Ministério da Saúde, 2003. p. 49.

${ }^{9}$ Artigos $1^{\circ}$, inciso III; 6 $6^{\circ}$ 23, inciso II; 24, inciso XII; e 196 a 200, todos da CF/88. BRASIL. Constituição da República Federativa do Brasil de 1988, cit.

${ }^{10}$ Recurso proposto, no prazo de cinco dias, contra a decisão do presidente do tribunal, de presidente de turma ou do relator, que causar prejuízo ao direito da parte, nos termos do disposto no artigo 317, do Regimento Interno do STF.

${ }^{11}$ Decisão concedida ainda no início da demanda, uma vez preenchidos os requisitos legais, no intuito de assegurar a eficácia do futuro provimento jurisdicional, ou então, antecipar, desde logo, a tutela de natureza satisfativa que somente seria deferida ao final do processo.
} 
indeferimento de idêntica ordem levado a efeito pelo Tribunal Regional Federal da $5^{a}$ Região. A decisão do STF obrigou, antes do final do trâmite da ação civil pública originária, que o Município de Petrolina, com o auxílio do aludido Estado e da União, realizasse providências administrativas, hábeis a promover a melhoria do atendimento proporcionado aos usuários do Sistema Único de Saúde (SUS) pelo Hospital Dom Malan.

As razões recursais de Pernambuco amparam-se no argumento de que o atendimento da decisão geraria grave lesão à ordem administrativa, à economia e à saúde pública, sobretudo porque obrigaria o "deslocamento de esforços e recursos estaduais" específicos para o cumprimento do determinado judicialmente, a ponto de gerar a "descontinuidade da prestação dos serviços de saúde em outros postos de atendimento". Ao seu turno, instado a se manifestar, o Ministério Público Federal posicionou-se contrariamente ao provimento do recurso, diante da ausência de elementos comprobatórios do alegado pelo Estado.

A seguir, ampliando consideravelmente a cognição processual reservada ao julgamento do agravo regimental manejado e extrapolando o próprio objeto do recurso $^{12}$, seu relator, Gilmar Mendes - sob a justificativa da "relevância da concretização do direito à saúde e da complexidade que envolve a discussão de fornecimento de tratamentos e medicamentos por parte do Poder Público, inclusive por determinação judicial" - entendeu que o caso concreto deveria ser apreciado sob perspectiva "mais ampla".

Dessa forma, levando-se em consideração as conclusões obtidas a partir da audiência pública realizada, passou-se, em síntese - depois de serem apresentadas breves ponderações sobre os limites e as possibilidades de implementação de questões sanitárias através da função jurisdicional -, a promover a interpretação de diversos pontos da seção reservada à saúde na $\mathrm{CF} / 88$, em especial os disciplinados no artigo 196, claramente intencionando esclarecer no que consiste cada um de seus elementos, através das seguintes subdivisões: "direito de todos"; "dever do Estado"; "garantido mediante políticas sociais e econômicas"; "políticas que visem à redução do risco de doença e de outros agravos"; "políticas que visem ao acesso universal e igualitário" e "ações e serviços para promoção, proteção e recuperação da saúde".

Em acréscimo, novamente amparando-se no que sobressaiu do ato público realizado pelo STF, pontuou-se que:

(a) na generalidade dos casos, não há interferência do Poder Judiciário na criação e implementação de políticas públicas em matéria de saúde, mas sim apenas a determinação judicial acerca do efetivo cumprimento de políticas públicas existentes;

${ }^{12}$ Restrito ao fato de que a decisão questionada gerou grave lesão à ordem administrativa, à economia e à saúde pública, inclusive com a possibilidade de acarretar desatendimento em outras unidades de saúde. 
(b) no trato da dispensação de medicamentos, a não ser em casos excepcionais, apresenta-se vedado à Administração Pública fornecer fármaco carente de registro na Agência Nacional de Vigilância Sanitária (Anvisa); há a necessidade de privilegiar o tratamento fornecido pelo SUS, sempre que, motivadamente, não restar comprovada a ineficácia ou a impropriedade da política de saúde vigente; e, por fim,

(c) deve-se promover a revisão periódica dos protocolos de tratamento existentes.

Na sequência, ao retomar de maneira expressa e específica as razões do agravo regimental apenas na parte final do voto, a Relatoria, bem objetivamente, reconheceu a ausência de demonstração do perigo de grave lesão alegado e salientou que, em verdade e com base na possibilidade de "dano inverso", o atendimento do recurso implicaria danosas consequências aos munícipes que dependem do Hospital Dom Malan para tratarem da saúde, assim negando provimento à pretensão recursal.

$\mathrm{O}$ voto proferido foi efusivamente elogiado e acolhido pelos demais ministros da Corte, sendo certo que, do pronunciamento de Celso de Mello - o que, em longo arrazoado, mais discorreu a respeito -, ainda é possível inferir acréscimos interpretativos no sentido de que o STF, em razão da dimensão política da jurisdição constitucional outorgada ao Tribunal, aliada ao "alto significado social e o irrecusável valor constitucional" do direito à saúde, não se pode eximir "do gravíssimo encargo" de torná-lo efetivo, "se e quando os órgãos estatais competentes" vierem a comprometer sua "eficácia e integridade".

Também afirmou não haver discricionariedade administrativa nesses casos, inexistindo a possibilidade de acolher a denominada "cláusula da reserva do possível" na hipótese específica - posto que, entre proteger a vida e a saúde e fazer prevalecer um "interesse financeiro e secundário do Estado", alegações de ordem ético-jurídicas impõem a obrigatoriedade de se respeitarem as primeiras. Asseverou que, em verdade, quando o STF supre “omissões" dos órgãos estatais, nada mais faz senão cumprir sua missão institucional e honrar a "autoridade da Lei Fundamental da República”, evitando a ocorrência de retrocesso em matéria de importância social.

$\mathrm{E}$, assim, de maneira unânime, desproveu-se o agravo regimental ${ }^{13}$, tornando necessário na sequência expender comentários de duas ordens, a partir do então decidido.

Primeiro, houve clara e emblemática opção do STF por ocupar espaço na arena política, pois utilizando o entendimento retratado no julgado, encampado de

\footnotetext{
${ }^{13} \mathrm{~A}$ ementa restou assim definida: “Suspensão de Liminar. Agravo Regimental. Saúde pública. Direitos fundamentais sociais. Art. 196 da Constituição. Audiência Pública. Sistema Único de Saúde-SUS. Políticas públicas. Judicialização do direito à saúde. Separação de poderes. Parâmetros para solução judicial dos casos concretos que envolvem direito à saúde. Responsabilidade solidária dos entes da Federação em matéria de saúde. Ordem de regularização dos serviços prestados em hospital público. Não comprovação de grave lesão à ordem, à economia, à saúde e à segurança pública. Possibilidade de ocorrência de dano inverso. Agravo regimental a que se nega provimento". STF. Tribunal Pleno. SL 47 AgR/PE. Rel. Min. Gilmar Mendes. J. em 17.3.2010. Pub. em 29.4.2010.
} 
maneira unânime por seus membros, passou a determinar a realização de posturas que antes ficavam restritas à atuação do Legislativo e do Executivo.

Melhor explicando, mostra-se de todo certo procurar extrair da norma constitucional o máximo valor normativo possível, assim inviabilizando que permaneça, por exemplo, carente de efetividade.

De igual modo, apresenta-se correto que, uma vez previsto constitucionalmente, o direito possa ser exigível tanto do poder público quanto do privado e, caso não seja respeitado ou atendido, o próprio sistema constitucional no regime democrático brasileiro previu a possibilidade de acesso ao Judiciário ${ }^{14}$ para garantir sua adequada tutela.

No entanto, o atual cenário do constitucionalismo - ora compreendido como o movimento estabelecido com o propósito de legitimar o poder através da instituição de Constituição que se corporifique em documento escrito, faça prevalecer a superioridade do Estado de Direito ${ }^{15}$ e estabeleça normas capazes de limitar e moderar o poder político ${ }^{16}$-, e da democracia - enquanto governo que "emana" da maioria, sem deixar de respeitar a minoria, facilitando a participação dos cidadãos na decisão das políticas a serem seguidas, a bem de efetivamente garantir a soberania popular $^{17}$-, impõe atenta e crítica reflexão sobre a intervenção do STF nos casos em que determina a execução de políticas públicas ou a invalida atividade administrativa.

Nesses termos, a partir do constitucionalismo vigente, percebe-se que a própria $\mathrm{CF} / 88$ destaca o STF como órgão encarregado, na arquitetura institucional,

\footnotetext{
${ }^{14}$ Artigo $5^{\circ}$, inciso XXXV, da CF/88. BRASIL. Constituição da República Federativa do Brasil de 1988, cit. Aliás, costuma-se dizer que: "A origem polêmica remonta a Hamilton, que nos Artigos Federalistas 78 a 83 pôs-se a defender a condição privilegiada dos juízes e o papel político do Judiciário na ousada engenharia institucional da Constituição elaborada na Filadélfia. A dificuldade central era: o mesmo movimento que pretendia construir a primeira nação democrática moderna, assentada no governo do povo, parecia elevar a magistratura à condição de corpo independente e reservar ao Judiciário a função contramajoritária de preservar a constituição frente aos atos dos poderes políticos representativos da soberania popular". ARANTES, Rogério Bastos. Prefácio. In: POBREBINSCHI, Thamy. Judicialização ou representação?: política, direito e democracia no Brasil. Rio de Janeiro, 2011.

${ }^{15} \mathrm{~A}$ respeito, ao conciliar constitucionalismo com Estado de Direito, esclarece Weingast: "One of the central features os limited government is the rule of law, a society of universalists laws, not of discretionary political power. The above model provides a new approach to the microfoundations of the rule of law. Because laws and political limits can be disobeyed or ignored something beyond laws is necessary to prevent violations. To survive, the rule of law requires limits on political officials be self-enforcing. As we have seen, self-enforcement of limits depends on the complementary combinations of attitudes and reactions of citizens as well as institutional restrictions". ("Uma das características centrais do governo limitado é o Estado de Direito, uma sociedade de leis universalistas, não de poder político discricionário. O modelo acima fornece uma nova abordagem para as micro fundações do Estado de Direito. Pelo fato de que as leis e os limites políticos podem ser desobedecidos ou ignorados, algo além das leis é necessário para evitar violações. Para sobreviver, o Estado de Direito exige que limites sobre os agentes políticos sejam autoexecutáveis. Como vimos, a autoaplicação dos limites dependem das combinações complementares de atitudes e reações dos cidadãos, assim como de restrições institucionais" [tradução livre]). WEINGAST, Barry. The political foundations of democracy and the rule of law. The American Political Science Review, v. 91, n. 2, p. 263, Jun. 1997.

${ }^{16}$ CANOTILHO, J. J. Gomes. Direito constitucional e teoria da Constituição. 2. ed. Coimbra: Almedina, 1998. p. 46.

${ }^{17}$ Sobre o assunto, ver CÓLON-RIOS, Joel I. The second dimension of democracy: the people and their constitution. Baltic Journal of Law \& Politics, v. 2, n. 2, 2009.
} 
de efetuar a guarda de seus ditames (artigo 102). Esse múnus traduz importante feição jurídico-política, sobretudo quando aprecia a judicialização de políticas ${ }^{18}$.

Por isso, nas ocasiões em que o STF necessita julgar, sua atividade, na salutar interação que deve existir entre as funções estatais, obrigatoriamente precisa ser comedida, útil e resolutiva, livre de retóricas indevidas, sob pena de seus julgados, ao invés de promoverem a supremacia e a tutela da normatividade constitucional, acabarem se mostrando excessivos e arbitrários, desequilibrando onde em essência deveria obrigatoriamente equilibrar.

Logo, agirá válida e legitimamente o STF quando bem exercer a tutela constitucional, fugindo de apresentar ato indicador do exclusivo interesse desse próprio órgão julgador, preocupando-se em seguir o querer do constituinte ou do legislador e, sobretudo, procurando se aproximar do prevalente no meio social, de maneira a respeitar o regime democrático.

Ressaltados esses pontos, é possível adentrar a seguir, e de maneira mais pormenorizada, na apreciação do julgamento resultante da interposição de agravo.

Em segundo lugar, a decisão ora em destaque recebeu diversas análises, as quais, diante dos limites restrito deste trabalho, podem ser divididas em quatro grupos, a partir das conclusões a que chegaram. O primeiro grupo, de âmbito mais restrito, investigou e concluiu que os argumentos contidos nos discursos proferidos na audiência pública citada foram acolhidos pelo STF quando do julgamento da $\mathrm{SL} 47-\mathrm{AgR} / \mathrm{PE}^{19}$. O segundo, assumindo postura totalmente contrária ao desfecho produzido, assinalou que a situação destacada na jurisprudência selecionada revela que, além de o Judiciário atuar em questões consideradas de competência exclusiva do Executivo e do Legislativo, "a Suprema Corte brasileira não possui nenhuma teoria da justiça, no sentido de que não possui critérios claros, coerentes e equânimes para promover uma adequada distribuição de recursos”, mostrando-se certo que a intervenção acentuada do Poder Judiciário tem causado, no mínimo, diversas distorções ao próprio sistema público de saúde ${ }^{20}$. O terceiro, reconhecendo um "remodelamento da função judicial", aduziu que o Judiciário vem sendo cada vez mais provocado a interferir e atuar na dimensão política, na condição de protetor das "problemáticas sociais" - o que constitui uma tendência de que, "em caso de

\footnotetext{
${ }^{18} \mathrm{Em}$ percuciente análise, afirmou-se: “la judicialización de la política es más probable donde la legitimidad del régimen está vinculada crecientemente a la capacidad de garantizar las promesas de derechos, em debido processo y la rendición de cuentas". SIEDER, Rachel, SCHJOLDEN, Line; ANGELL, Allan. Introduction. In: SIEDER, Rachel, SCHJOLDEN, Line; ANGELL, Allan (Eds.). The judicialization of politics in Latin America. Palgrave Macmillan. 2005. p. 18.

${ }^{19}$ SANTOS, Alethele de Oliveira Santos; MARQUES, Silvia Badim. A abordagem de aspectos jurídicos na Audiência Pública da Saúde do Supremo Tribunal Federal. Cadernos Ibero-Americanos de Direito Sanitário, Brasília, v. 3, n. 3, p. 1-24, out/dez. 2014

${ }^{20}$ CUNHA FILHO, Márcio Camargo. Qual é a justiça da justiça brasileira? Uma análise das decisões do supremo tribunal federal em matéria de direito à saúde à luz das teorias políticas de R. Nozick, J. Rawls e R. Dworkin. Revista Direito e Práxis, v. 4, n. 7, p. 172-195, 2013.
} 
omissão governamental", as políticas públicas sejam efetivadas no âmbito judicial21 ${ }^{21}$. Por fim, o quarto grupo, integralmente a favor do papel desenvolvido pelo STF e de todo o decidido, atesta que o decisum prolatado "consolidou de vez a impertinência do argumento da reserva do possível e de outras frequentes teses de defesa do poder público, quando confrontadas com o direito à saúde"22, tendo também se mostrado apto a fornecer importantes "parâmetros que devem conduzir" as decisões judiciais ${ }^{23}$.

Todavia, a partir do exame do processado no âmbito do SL 47-AgR/PE, diversamente das conclusões a que chegaram as análises citadas, pretende-se, in casu, apenas verificar teoricamente se o julgado reúne condições de representar acerto jurídico e político, de forma a produzir positivas repercussões.

Com efeito, o direito à saúde deve se concretizar, inclusive diante do disposto no artigo 196, primordialmente por intermédio de políticas sociais e econômicas, de maneira que a atuação jurisdicional - a partir do previsto constitucionalmente, do ideal democrático, quando e se necessária - deve ser discreta, equilibrada, responsável e séria, sem abusos ou excessos, pois, no desenho institucional constante do âmbito constitucional, a tarefa precípua de implementá-las pertence à Administração Pública.

Não obstante, após a edição da $\mathrm{CF} / 88$, passou-se a registrar na agenda de debates e julgamentos levados a efeito pelo Judiciário - os quais, repita-se, necessitam seguir os preceitos afetos ao constitucionalismo e à democracia - e, em especial, pelo STF, inúmeras demandas cujo objeto é a saúde.

A excessiva judicialização de políticas públicas, acrescida da natural complexidade das questões que as circundam, é decorrente da necessidade inafastável de constantemente procurar harmonizar a supremacia da Constituição com os preceitos norteadores da "separação de poderes" ${ }^{24}$. A ponderação acerca dos bens e valores constitucionais em discussão e a preocupação de não comprometer a política de saúde como um todo e, mais, de garantir fiel respeito aos princípios e diretrizes do SUS demonstram que a convocação da audiência pública por parte do STF teve grande valor e significado.

\footnotetext{
${ }^{21}$ ALBUQUERQUE, Felipe Braga. Direito \& política: pressupostos para a análise de questões políticas pelo judiciário à luz do princípio democrático. Florianópolis: Conceito, 2013. p. 181-182.

${ }^{22}$ MAPELLI JÚNIOR, Reynaldo; COIMBRA, Mário; MATOS, Yolanda Alves Pinto Serrano de. Direito sanitário. São Paulo: Ministério Público, 2012. p. 121.

${ }^{23}$ TORROTENGUY, Marco Aurélio Antas. A saúde nas barras da justiça: um estudo do posiconamento recente do Supremo Tribunal Federal. Revista de Direito Sanitário, São Paulo, v. 11, n. 2. p. 235, jul./out. 2010. Disponível em: <http://www.revistas.usp.br/rdisan/article/view/13215>. http://dx.doi.org/10.11606/ issn.2316-9044.v11i2p224-236.

${ }^{24}$ Compreendida "como una forma de la división del trabajo, que permita una distribución y una organización mas eficientes de las funciones gubernamentales". [...] El equilíbrio constitucionalmente impuesto puede hacer que el gobierno em conjunto sea (algo parecido a un barómetro) mucho más sensible a las fluctuaciones de la opinión publica de lo que sería cualquier régimen de uma sola rama. Tambien en este sentido, los frenos y equilíbrios pueden contribuir directamente a la soberanía popular". HOLMES, Stephen. El precompromiso y la paradoja de la democracia. In: ELSTER, Jon; SLAGSTAD, Rune (Eds.). Constitucionalismo y democracia. México: Fondo de Cultura Económica, 2001. p. 249-251.
} 
Os subsídios técnicos colhidos nesse ato público, oriundos de representantes de diversas áreas do saber e da sociedade, foram levados em consideração pelo STF no julgamento da SL 47-AgR/PE e contribuíram para o resultado final produzido. Ao seu turno, o decidido não deixou de representar sensível avanço no trato das ações e serviços de saúde, pois, a partir do julgamento concreto proferido - torna-se a registrar, lastreado nos dados produzidos a partir da audiência pública realizada -, o Judiciário passou a garantir maior eficiência e justiça nas soluções das demandas judiciais envolvendo a assistência à saúde nas decisões que se sucederam ${ }^{25}$, o que levou inclusive o Conselho Nacional de Justiça (CNJ) a editar, após “diálogo interinstitucional”, a Recomendação n. 31/2010 e muitos enunciados sobre saúde ${ }^{26}$.

A partir desses efeitos, incentivaram-se o Legislativo e o Executivo a também atuar nesse sentido, o que proporcionou a entrada de regramento em vigor e a execução de políticas concretizadoras de assistência terapêutica, de financiamento mais adequado à saúde, além da incorporação de tecnologia em saúde no âmbito do SUS, com articulação interfederativa, respectivamente ${ }^{27}$, assim assegurando melhor

\footnotetext{
${ }^{25}$ Conferir os seguintes julgamentos do próprio STF baseados no decidido no âmbito da SL 47 AgR-PE: STF. ARE 855762 AgR/RJ. $2^{\text {a }}$ T. Rel. Min. Gilmar Mendes. J. 19.5.105. DJ 29.5.2015; STF. RE 810603 AgR/RN. $2^{\mathrm{a}}$ T. Rel. Min. Cármen Lúcia. J. 19.8.2014. DJ 27.8.2014; STF. RE 792612 ED/RN. 2ª T. Rel. Min. Cármen Lúcia. J. 1.4.2014. DJ 10.4.2014; ARE 740800 AgR/RS. 2a T. Rel. Min. Cármen Lúcia. J. 3.12.2013. DJ 11.1.2013 e STF. RE 642536 AgR/AP. $1^{\text {a }}$ T. Rel. Min. Luiz Fux. J. 5.2.2013. DJ 26.2.2013, por exemplo. Por sua vez, alicerçado no SL 47 AgR-PE, destacam-se os julgamentos do TJSP: Reexame Necessário nº 0002504-82.2015.8.26.0024. $2^{a}$ Câm. de Dir. Público. Rel. Des. Renato Delbianco. J. em 1.12.2015. DJ de 3.12.2015; TJSP: Agravo n 0008838-24.2011.8.26.0655. 10ª Câm. de Dir. Público. Rel. Des. Teresa Ramos Marques. J. 30.11.2015. DJ. 2.12.2015; Apelação n ${ }^{\circ}$ 0000243-71.2015.8.26.0210. $1^{\text {a }}$ Câm. de Dir. Público. Rel. Des. Vicente de Abreu Amadei. J. 24.11.2015. DJ. 25.11.2015 e TJSP. Agravo de Instrumento $n^{\circ}$ 2220105-58.2015.8.26.0000. $3^{\mathrm{a}}$ Câm. de Dir. Público. Rel. Des. Amorim Cantuária. J. 24.11.2015. DJ. 25.11.2015. Em idêntico sentido, mas agora junto ao TJPR: Apelação $n^{\circ}$ 130224-6. $4^{\text {a }}$ Câm. Cível. Rel. Des. Maria Aparecida Blanco de Lima. J. 12.5.2015. DJ de 22.5.2015; TJPR. Susp. de Liminar n 1354410-4. Órgão Especial. Rel. Des. Paulo Roberto Vasconcelos. J. 25.3.2015. DJ de 31.3.2015; TJPR. Agr. Inominado. Rel. Des. Abraham Lincoln Calixto. J. 6.8.2013. DJ. 16.10.2013 e TJPR. Apelação $n^{\circ}$ 740652-0. 3ª Câm. Cível. Rel. Des. Ruy Francisco Thomaz. J. 18.10.2011. DJ 27.10.2011.

${ }^{26}$ Capazes de serem consultados através dos seguintes endereços eletrônicos: ENUNCIADOS aprovados na I Jornada de Direito da Saúde do Conselho Nacional de Justiça em 15 de maio de 2014 - São Paulo-SP. Disponivel em: <http://www.cnj.jus.br/images/ENUNCIADOS_APROVADOS_NA_JORNADA_DE_DIREITO_ DA_SAUDE_\%2OPLENRIA_15_5_14_r.pdf>. Acesso em: 09 dez. 2015 e JORNADA DE DIREITO À SAÚDE, 2. Disponivel em: <http://www.cnj.jus.br/files/conteudo/destaques/arquivo/2015/05/96b5b10aec7e5954 fcc1978473e4cd80.pdf>. Acesso em: 09 dez. 2015.

${ }^{27}$ Verificar: BRASIL. Lei n. 12.401, de 28 de abril de 2011. Altera a Lei no 8.080, de 19 de setembro de 1990, para dispor sobre a assistência terapêutica e a incorporação de tecnologia em saúde no âmbito do Sistema Único de Saúde - SUS. Disponivel em: <http://www.planalto.gov.br/CCIVIL_03/_Ato2011-2014/2011/Lei/L12401.htm>. Acesso em: 31 jan. 2017. BRASIL. Lei Complementar n. 141, de 13 de janeiro de 2012. Regulamenta o $\S 3^{\circ}$ do art. 198 da Constituição Federal para dispor sobre os valores mínimos a serem aplicados anualmente pela União, Estados, Distrito Federal e Municípios em ações e serviços públicos de saúde; estabelece os critérios de rateio dos recursos de transferências para a saúde e as normas de fiscalização, avaliação e controle das despesas com saúde nas 3 (três) esferas de governo; revoga dispositivos das Leis nos 8.080 , de 19 de setembro de 1990, e 8.689, de 27 de julho de 1993; e dá outras providências. Disponível em: <http://www.planalto.gov.br/ccivil_03/leis/LCP/Lcp141. htm>. Acesso em: 31 jan. 2017. BRASIL. Decreto n. 7.508, de 28 de junho de 2011. Regulamenta a Lei $n^{\circ} 8.080$, de 19 de setembro de 1990, para dispor sobre a organização do Sistema Único de Saúde - SUS, o planejamento da saúde, a assistência à saúde e a articulação interfederativa, e dá outras providências. Disponivel em: <http://www. planalto.gov.br/ccivil_03/_ato2011-2014/2011/decreto/D7508.htm>. Acesso em: 31 jan. 2017.
} 
simetria entre os benefícios a que fazem jus os usuários da rede pública de saúde, os custos necessários à implantação e o respeito à gestão sanitária.

Aliás, a interpretação que o STF realizou do artigo 196 da CF/88 e de outros temas afetos à prestação de ações e serviços de saúde está próxima do querer do Constituinte originário, visto que a seção reservada à saúde no texto constitucional sofreu forte influência do deliberado na $8^{\text {a }}$ Conferência Nacional de Saúde, realizada de 17 a 21 de março de 1986, e que a fundamentação constante dos votos e encampada pelos Ministros da Corte à época guarda sintonia com o constante no Relatório Final desse fórum democrático ${ }^{28}$.

Portanto, as repercussões foram e ainda são bem positivas. No entanto, observa-se pela simples leitura da íntegra do acórdão confeccionado que ao menos um aspecto, embora restrito à órbita processual, poderia ter sido evitado. Com efeito, o agravo regimental utilizado pelo Estado de Pernambuco com o propósito de questionar a decisão do Presidente do STF e, assim, alcançar a suspensão dos efeitos de liminar proferida tinha limite restrito à "grave lesão à ordem e à economia pública", além de ofensa à "separação de poderes". Todavia, o debate e a fundamentação propriamente a respeito da irresignação recursal ocuparam pequena parte do voto externado pelo Relator. Ao seu turno, os demais Ministros apenas se limitaram, no tocante ao agravo interposto, em acompanhar a Relatoria, assim negando-lhe provimento. A discussão maior e, nesse ponto, ampla voltou-se ao direito à saúde, a algumas políticas que lhe são afetas - sobretudo a relativa à assistência farmacêutica - e ao papel do Judiciário frente à judicialização dessas matérias. Para a situação concreta, portanto, argumentou-se e decidiu-se além do que seria preciso, talvez na ânsia de estabelecer parâmetros capazes de viabilizar solução judicial mais adequada frente aos casos que envolviam e envolvem o direito à saúde. Enquanto corolário, do ponto de vista estritamente processual, o pronunciamento do STF no SL 47-AgR/PE pode ser considerado excessivo, não comedido e desarrazoado, contendo comandos ultra e extra petita ${ }^{29}$.

Mas essa constatação serve para retirar o brilho jurídico do julgado? Não, pois houve respeito sistêmico ao disposto no âmbito constitucional, inclusive a ponto de assegurar exemplar juridicidade ao definido a partir do artigo 196 da $\mathrm{CF} / 88$. De igual modo, no campo político - e o STF exerce, consoante explicitado, atividade política $^{30}$-, observa-se que o decisum correspondeu às demandas e aos

\footnotetext{
${ }^{28}$ Conferir CONFERÊNCIA NACIONAL DA SAÚDE, 8. Disponível em: <http://bvsms.saude.gov.br/bvs/ publicacoes/8_conferencia_nacional_saude_relatorio_final.pdf>. Acesso em: 23 set. 2015.

${ }^{29}$ Além e fora do delimitado pelo agravante (Estado de Pernambuco).

${ }^{30}$ Conclusivamente, afirma Sadek que protagonismo judicial sobre políticas públicas "ao mesmo tempo em que garante a conversão dos preceitos legais - definidores do âmbito da igualdade - em realidade, fortalecem a presença da magistratura, construindo uma identidade distante daquela do juiz boca da lei. O juiz inanimado cedeu espaço para o magistrado ator político de expressão". SADEK, Maria Tereza. O judiciário e arena pública: um olhar a partir da ciência política. In: GRINOVER, Ada Pellegrini (Coord.). O controle jurisdicional de políticas públicas. Rio de Janeiro: Forense, 2011.
} 
anseios sociais ainda em vigor, destacando importantes diretrizes sobre o direito à saúde e suas políticas, de maneira que a mudança de status quo produzida encontrou reverberação e correspondência não só nos planos judicial, executivo e legislativo, mas também perante a realidade social.

Ademais, não se ateve a Corte, enquanto resultado da audiência pública, aos seus próprios interesses, comprovadamente contribuindo, através de indicadores e balizas que apresentou, para o aperfeiçoamento da atividade executiva e legislativa - as quais, inclusive e em decorrência, consoante demonstrado, melhoraram as regras normativas pertinentes à assistência, ao financiamento e à incorporação de novas tecnologias em benefício dos usuários do SUS, bem como aceitaram ampliar o diálogo interinstitucional nessa seara.

Tanto é verdade que, ainda como consequência - sem os exageros que os padrões oriundos da decisão, por outro lado, conseguiram evitar, como por exemplo o fornecimento despropositado, através de ordem judicial, de medicamentos ainda em fase experimental, sem qualquer comprovação científica de seus benefícios ou a autorização carente de justificativa para a oferta de tratamento escolhido pelo paciente, em desprestígio daquele dispensado pelo SUS -, a Administração Pública vem conseguindo melhor executar atos de gestão, planejamento e controle relacionados às ações e serviços de saúde.

E, nesses termos, a situação concreta, ainda que formalmente em desprestígio da boa técnica processual, instrumentalmente procurou e conseguiu fazer as pazes com o jurídico-constitucional e a política, claramente incrementando e fortalecendo a dignidade humana, bem como contribuindo exemplarmente para a boa administração pública da causa sanitária ${ }^{31}$ - tanto que ainda continua a ser objeto de referência paradigmática nas situações em que não conseguiu distanciar-se da judicialização.

\section{Considerações finais}

A existência de um Judiciário proativo quando sua atuação for indispensável, diverso de neutralidade e indiferença, parece ser condição necessária e um inevitável produto do constitucionalismo e da democracia após a segunda metade do século XX, pois é fruto de lutas que deram forma e significado ao atual sistema

\footnotetext{
${ }^{31} \mathrm{~A}$ proeminência do STF no cenário institucional, também derivada da judicialização de políticas no Brasil, acarreta a possibilidade de simplesmente rechaçá-la, contribuindo para a manutenção da "situação exatamente como ela se apresenta faticamente" ou, então, aceitar tal fato e, desse modo, assumir esse natural movimento integrante da evolução democrática, não interpretando-o "como uma ameaça à representação política, às instituições representativas ou à democracia; mas, ao contrário, como um sinal de que a primeira precisa ser ressignificada, as segundas reconfiguradas e a terceira fortalecida". Nesse contexto, apresenta-se como melhor alternativa a criação de soluções institucionais capazes de assegurar à atuação jurisdicional representatividade, "a despeito da inaplicabilidade do dispositivo eleitoral enquanto mecanismo de legitimação e accontability”. POBREBINSCHI, Thamy. op. cit., p. 175.
} 
político. Além disso, é derivação de fatores eminentemente políticos e não propriamente judiciais, ao se perceber com maior nitidez que dividir responsabilidade com as cortes se tornaria uma opção interessante à classe política ${ }^{32}$.

Do ponto de vista jurídico e político, concretamente, ousa-se afirmar que a escolha adotada pelo STF não foi "trágica", mas sim estratégica, posto que, no balanceamento e ponderações escolhidos, construiu e fortaleceu - ao invés de destruir e enfraquecer - sensíveis, significativos e valiosos pontos de relacionamento com o Legislativo, o Executivo e também a sociedade.

Não obstante a constatação de impropriedade sob o enfoque formal-processual, jurídica e politicamente a tensão instaurada e relacionada à implantação de políticas públicas por intermédio da intervenção do Judiciário restou bem equacionada pelo STF na SL 47-AgR/PE, pois as providências adotadas para apreciá-lo e os resultados obtidos indicam que os "custos" decorrentes, em verdade, serviram para garantir maior segurança aos cidadãos e às próprias instituições encarregadas de legislar e executar ações e serviços de saúde. Tal conclusão ratifica a afirmação de Ginsburg: "A expansão do poder judicial em todo o mundo reflete democratização e não é antidemocrática como sugerido por alguns analistas. A revisão judicial pode ser contramajoritária, mas não é contrademocrática"33 (tradução livre).

Reconhece-se a impossibilidade de generalizar, mas, no caso concreto, não houve intrusão do Judiciário nas prerrogativas do Legislativo e do Executivo, até porque, conforme revelado, a fundamentação e a decisão judicial examinadas asseguraram positivo impacto e verdadeiramente auxiliaram o Poder Público a melhor operacionalizar seus próprios interesses no campo da saúde, inclusive pragmaticamente com a edição de leis e a adoção de adequados parâmetros para a gestão da saúde.

A somatória desses fatores reforça o caráter paradigmático do SL 47-AgR/PE.

Portanto, ao contrário do que se poderia supor, a representatividade jurídica e política oriunda da atuação do STF mostrou-se caracterizada, servindo ainda de exemplo para o fortalecimento constitucional-sanitário do direito à saúde. Fica como desafio para além dos limites deste trabalho identificar, de maneira geral, quais pressupostos ou elementos normalmente podem indicar a presença de representatividade jurídica e política na atuação jurisdicional, já que conforme anteriormente afirmado, ainda não se dispõe "de uma visão sistemática e coerente acerca do trabalho da Corte" ${ }^{\text {"34. }}$.

${ }^{32} \mathrm{HIRSCHL}$, Ran. Towards juristocracy: the origins and consequences of the new constitutionalism. Harvard University Press, 2004. p. 32-40, passim.

33" The expansion of judicial power around the globe reflects democratization and is not antidemocratic as suggested by some analysts. Judicial review may be countermajoritarian but is not counterdemocratic". GINSBURG, Tom. Judicial review in new democracies: constitutional courts in Asian cases. Cambridge: Cambridge University Press, 2003. p. 31.

${ }^{34}$ ARANTES, Rogério Bastos. Cortes constitucionais. In: AVRITZER, Leonardo, BIGNOTTO, Newton, FIGUEIRAS, Fernando, GUIMARÃES, Juarez; STARLING (Orgs). Dimensões políticas da Justiça. Rio de Janeiro: Civilização Brasileira, 2013. p. 203. 


\section{Referências}

ALBUQUERQUE, Felipe Braga. Direito \& política: pressupostos para a análise de questões políticas pelo judiciário à luz do princípio democrático. Florianópolis: Conceito, 2013.

ARANTES, Rogério Bastos. Cortes constitucionais. In: AVRITZER, Leonardo, BIGNOTTO, Newton, FIGUEIRAS, Fernando, GUIMARÃES, Juarez; STARLING (Orgs). Dimensões políticas da Justiça. Rio de Janeiro: Civilização Brasileira, 2013.

Prefácio. In: POBREBINSCHI, Thamy. Judicialização ou representação?: política, direito e democracia no Brasil. Rio de Janeiro, 2011.

CANOTILHO, J. J. Gomes. Direito constitucional e teoria da Constituição. 2. ed. Coimbra: Almedina, 1998.

CÓLON-RIOS, Joel I. The second dimension of democracy: the people and their constitution. Baltic Journal of Law \& Politics, v. 2, n. 2, 2009.

CONFERÊNCIA NACIONAL DA SAÚDE, 8. Disponível em: <http://bvsms.saude.gov. br/bvs/publicacoes/8_conferencia_nacional_saude_relatorio_final.pdf $>$. Acesso em: 23 set. 2015.

CUNHA FILHO, Márcio Camargo. Qual é a justiça da justiça brasileira? Uma análise das decisões do supremo tribunal federal em matéria de direito à saúde à luz das teorias políticas de R. Nozick, J. Rawls e R. Dworkin. Revista Direito e Práxis, v. 4, n. 7, p. 172-195, 2013.

DALLARI, Sueli Galdolfi. Direito sanitário. In: MINISTÉRIO DA SAÚDE. Direito sanitário e saúde pública. Brasília: Ministério da Saúde, 2003.

O direitoà saúde. Revista de Saúde Pública, São Paulo, v. 22,n. 1,p. 57-63, 1988. Disponível em: $<$ http://www.scielo.br/pdf/rsp/v22n1/08.pdf >.http://dx.doi.org/10.1590/S0034-89101988000100008.

. A saúde do brasileiro. São Paulo: Moderna, 1987.

ENUNCIADOS aprovados na I Jornada de Direito da Saúde do Conselho Nacional de Justiça em 15 de maio de 2014 - são paulo-SP. Disponível em: <http://www.cnj.jus.br/ images/ENUNCIADOS_APROVADOS_NA_JORNADA_DE_DIREITO_DA_SAUDE_\%20 PLENRIA_15_5_14_r.pdf>. Acesso em: 09 dez. 2015.

GINSBURG, Tom. Judicial review in new democracies: constitutional courts in Asian cases. Cambridge: Cambridge University Press, 2003.

HIRSCHL, Ran. Towards juristocracy: the origins and consequences of the new constitutionalism. Harvard University Press, 2004.

HOLMES, Stephen. El precompromiso y la paradoja de la democracia. In: ELSTER, Jon; SLAGSTAD, Rune (Eds.). Constitucionalismo y democracia. México: Fondo de Cultura Económica, 2001. 
JORNADA DE DIREITO À SAÚDE, 2. Disponível em: <http://www.cnj.jus.br/files/conteudo/ destaques/arquivo/2015/05/96b5b10aec7e5954fcc1978473e4cd80.pdf>. Acesso em: 09 dez. 2015.

MAPELLI JÚNIOR, Reynaldo; COIMBRA, Mário; MATOS, Yolanda Alves Pinto Serrano de. Direito sanitário. São Paulo: Ministério Público, 2012.

POBREBINSCHI, Thamy. Judicialização ou representação?: política, direito e democracia no Brasil. Rio de Janeiro, 2011.

SADEK, Maria Tereza. O judiciário e arena pública: um olhar a partir da ciência política. In: GRINOVER, Ada Pellegrini (Coord.). O controle jurisdicional de políticas públicas. Rio de Janeiro: Forense, 2011.

SANTOS, Alethele de Oliveira Santos; MARQUES, Silvia Badim. A abordagem de aspectos jurídicos na Audiência Pública da Saúde do Supremo Tribunal Federal. Cadernos Ibero-Americanos de Direito Sanitário, Brasília, v. 3, n. 3, p. 1-24, out/dez. 2014.

SIEDER, Rachel, SCHJOLDEN, Line; ANGELL, Allan. Introduction. In: SIEDER, Rachel, SCHJOLDEN, Line; ANGELL, Allan (Eds.). The judicialization of politics in Latin America. Palgrave Macmillan. 2005.

TORROTENGUY, Marco Aurélio Antas. A saúde nas barras da justiça: um estudo do posiconamento recente do Supremo Tribunal Federal. Revista de Direito Sanitário, São Paulo, v. 11, n. 2. p. 224-236, jul./out. 2010. Disponível em: <http://www.revistas.usp.br/rdisan/article/ view/13215>. http://dx.doi.org/10.11606/issn.2316-9044.v11i2p224-236.

WEINGAST, Barry. The political foundations of democracy and the rule of law. The American Political Science Review, v. 91, n. 2, p. 245-263, Jun. 1997.

Sueli Gandolfi Dallari - Doutora, mestre e livre-docente em Saúde Pública pela Universidade de São Paulo; pós-doutora em Direito Médico pela Université de Paris XII (França) e em Saúde Pública pela Columbia University (EUA). Professora Titular da Universidade de São Paulo. Advogada. São Paulo/SP, Brasil.E-mail: sdallari@usp.br.

Marcelo Paulo Maggio - Doutorando em Saúde Pública pela Universidade de São Paulo; mestre em Direito pela Universidade Estadual de Londrina. Professor da Fundação Escola do Ministério Público do Paraná. Promotor de Justiça no Ministério Público do Paraná. Curitiba/PR, Brasil.E-mail: marcelopmaggio@gmail.com. 